\title{
Recorregut de recerca geològica i mineralògica per la comarca de l'Alt Urgell: des de Coll de Nargó a Fígols d’Organyà, Organyà i a la Palanca de Noves
}

Josep Maria Mata-Perelló

Joaquim Sanz Balagué

\section{XARAGALL REVISTA DE CIÈNCIES DE LA CATALUNYA CENTRAL n. 10}

OCTUBRE 2014 


\section{RECORREGUT DE RECERCA GEOLÒGICA I MINERALÒGICA PER LA COMARCA DE L'ALT URGELL: DES DE COLL DE NARGÓ A FÍGOLS D'ORGANYÀ, ORGANYÀ I A LA PALANCA DE NOVES}

\section{Josep Maria Mata-Perelló}

Museu de geologia Valentí Masachs, Escola Politècnica Superior d'Enginyeria de Manresa (EPSEM), Universitat Politècnica de Catalunya · BarcelonaTech (UPC), 08272 Manresa, Spain

\section{Joaquim Sanz Balagué}

Departament d'Enginyeria Minera i Recursos Naturals (EMRN), Escola Politècnica Superior d'Enginyeria de Manresa (EPSEM), Universitat Politècnica de Catalunya - BarcelonaTech (UPC), 08272 Manresa, Spain

Paraules clau: Sistema Pirinenc, Unitat Sudpirinenca Central, Mantell de la Zona de les Nogueres, Patrimoni miner

\section{Resum}

Itinerari realitzat el 19 d'octubre de 2013. En aquesta ocasió, el recorregut de l'itinerari discorrerà, en la seva quasi totalitat pel Sistema Pirinenc, i més concretament ho farà per la seva Unitat Sudpirinenca Central (tradicionalment anomenada amb el nom de les Serres Exteriors Prepirinenques). Així, el recorregut de l'itinerari s'iniciarà a la zona de contacte entre el Mantell del Montsec i el Mantell de Bóixols, a Coll de Nargó. A partir d'aquest indret, el recorregut de l'itinerari transitarà exclusivament pel darrer mantell esmentat. Tot i així, en arribar a les immediacions de la Palanca de Noves, a la fi del recorregut, s'arribarà al Mantell de la Zona de les Nogueres, per on finalitzarà el recorregut de l'itinerari.

També cal dir, que el recorregut de l'itinerari discorrerà per una sola comarca, concretament per la de l'Alt Urgell, des del principi a Coll de Nargó, fins a la fi del recorregut a la Palanca de Noves. 


\section{Objectius fonamentals}

Els objectius d'aquest itinerari es concretaran en diversos aspectes, geològics i mineralògics que apuntarem a continuació, d'acord amb el sentit de la marxa.

1. Estudi dels materials mesozoics (els quals es reparteixen desigualment entre el Triàsic, el Juràssic i el Cretàcic, amb un clar predomini dels terrenys d'aquest darrer) i cenozoics (de l'eocè), els quals constitueixen els relleus prepirinencs de la Unitat Sudpirienenca Central, que es tallen entre Coll de Nargó i les immediacions de Noves de Segre, dintre de l'alt Urgell. Aquests materials es distribueixen entre: el Mantell del Montsec i el Mantell de Bóixols. Tot i així, la major part del recorregut es realitzarà, quasi exclusivament pel segon mantell esmentat.

2. Reconeixement dels materials paleozoics del Mantell de la Unitat de les Nogueres, els quals es tallen exclusivament (dintre d'aquest itinerari), pels voltants de la Palanca de Noves (a la comarca de l'alt Urgell). Aquests materials es distribueixen entre el Permutaries i el Carbonífer.

3. Observació dels contactes entre les diferents unitats geològiques esmentades als apartats anteriors. I tanmateix entre els mantells també acabats d'esmentar.

4. Observació de les diferents mineralitzacions que anirem trobant al llarg del recorregut, com les mineralitzacions ferruginoses associades a lignits, que trobarem prop d'Organyà, entre els materials cretàcics. Cal dir que aquestes formacions carbonoses també es troben prop de Coll de Nargó.

5. Observació de les explotacions mineres relacionades amb les mineralitzacions anteriors, i d'altres com les següents:

$5 \mathrm{~A}$ ) dels materials al.luvials (de les terrasses del riu), per a ésser emprats com a àrids per a la construcció, que trobarem prop d'Oliana.

$5 \mathrm{~B})$ de les calcàries mesozoiques, de vegades per ésser emprades com a àrids, i de vegades per a la fabricació de ciment. Les trobarem entre Oliana y Coll de Nargó, i també pels voltants d'Organyà.

6. Observació de les restauracions (naturals o artificials) realitzades sobre les explotacions acabades d'esmentar.

7. Observació dels diferents indrets relacionats amb el nostre Patrimoni Geològic i amb el Patrimoni Miner, en concret dels relacionats amb els Forns de Calç i amb les Cimenteres. Ambdós elements es troben situats molt prop de la població del Coll de Nargó. 


\section{Antecedents}

En relació a aquest recorregut, coneixem de la existència de dos recorregut nostre. Es tracta del de Mata-Perelló (1995, 1998 i 2011). El primer descriu un recorregut entre Oliana i el Pla de Sant Tirs. El segon entre Oliana i la Palanca de Noves. I el tercer, un recorregut entre la Castellciutat i Peramola. També cal fer esment del treball de Mata-Perelló y Montané García (2002 i 2003). Tret d'aquests, no en coneixem l'existència de cap altre.

Pel que fa a les mineralitzacions que veurem en aquest itinerari, cal dir que ja estat prèviament descrites per nosaltres en Mata-Perelló (1991), en un treball relatiu al conjunt de les comarques catalanes.

I pel que fa a l'estructura geològica, ens remetrem als treballs de Riba et altri (1976), i a Guimerà et altri (1992). Tots dos fan referència al conjunt del caràcters geològics dels Països Catalans.

Així, totes aquestes referències bibliogràfiques es trobaran convenientment relacionades dintre del apartat dedicat a la REFERĖNCIES BIBLIOGRÀFIQUES, al qual ens remetem.

\section{Recorregut de l'itinerari}

El recorregut del present itinerari s'iniciarà a la població de Coll de Nargó, per on es faran les primeres aturades. Després, el recorregut es dirigirà cap el Nord, seguint la carretera C - 14. En arribar al Pont de l'Espià, ens caldrà primer agafar la carretera L - 401 i tot seguit la carretera local que es dirigeix cap a Fígols d'Organyà. En arribar a aquest poble, es farà una nova aturada.

Tot seguit, caldrà anar cap a Organyà, des d'on es continuarà cap el Nord, seguint de nou la carretera autonòmica $\mathrm{C}-14$. Per ella, es trobarà aviat el trencall de Montant de Tost i després el de Castellar de Tost, els dos per la dreta. També es trobarà per l'esquerra, el trencall d'Hostalets de Tost. Finalment, s'arribarà a la Palanca de Noves, per on finalitzarà el recorregut, despès de fer-se les darreres aturades.

\section{Advertiments previs}

Com en altres recorreguts de RECERCA GEOLÒGICA I MINERALÒGICA... si es disposa del temps suficient, poden efectuar-se passant per totes les parades i filloles. En cas contrari, recomanem prescindir de les anomenades PARADES - CONDICIONALS.

Per d'altra banda, el recorregut que ara presentarem, es pot combinar, si s'escau, amb reconeixements paleontològics per la comarca de I'Alt Urgell; i en especial, pels voltants de Coll de Nargó.

Recomanem, per d'altra banda, tenir una absoluta cura envers de la Natura, tant al llarg del recorregut, com fora d'ell, en tot moment. 


\section{Descripció de l'itinerari}

En aquest recorregut hem situat, com ja és habitual en tots els itineraris, una sèrie d'estacions o de PARADES, que anirem veient a continuació. En cada cas, els hi donarem una denominació que podrà correspondre a algun paratge proper.

Per d'altra banda, en cada una de les parades, indicarem entre parèntesi el número del "Mapa Topogràfic", a escala 1:50.000 editat per l'instituïu Geogràfic y Cadastral, on es troba situada la parada considerada. En aquesta ocasió serà algú dels dos següents: 253 (o d’organyà), i 291 (o d'Oliana). Així doncs, la relació ordenada de les aturades que formen part del recorregut del present itinerari, és el següent:

\subsection{Parada 1. SORTIDA DE COLL DE NARGÓ CAP EL NORD. CARRETERA AUTONÒMICA C - 14, (terme municipal de Coll de Nargó, comarca de l'Alt Urgell). (Full 291).}

El recorregut de l'itinerari, l’iniciarem a Coll de Nargó, per les immediacions de la cruïlla de les carreteres C - 14 (Oliana - la Seu) i L - 511 (Coll de Nargó - Isona). Des d'aquest indret, farem un curt recorregut cap el Nord, per la carretera C- 14. Just, a la sortida de la població, farem la primera aturada. Així, haurem fet un recorregut inferior a 0 ’ $5 \mathrm{Km}$ de l'inici de l'itinerari.

En aquest recorregut, hem trobat afloraments dels materials cenozoics, els quals formen part de la part superior del Mantell del Montsec. Tot i així, a l'indret de l'aturada, podem veure el contacte entre aquests materials i els cretàcics del Mantell de Bóixols, situats al Nord d'on ara som. (fotografia 1 ).

Per d'altra banda, des d'aquest indret, mirant cap a llevant, es pot veure l'Anticlinal d'Alinyà. (fotografia 2).

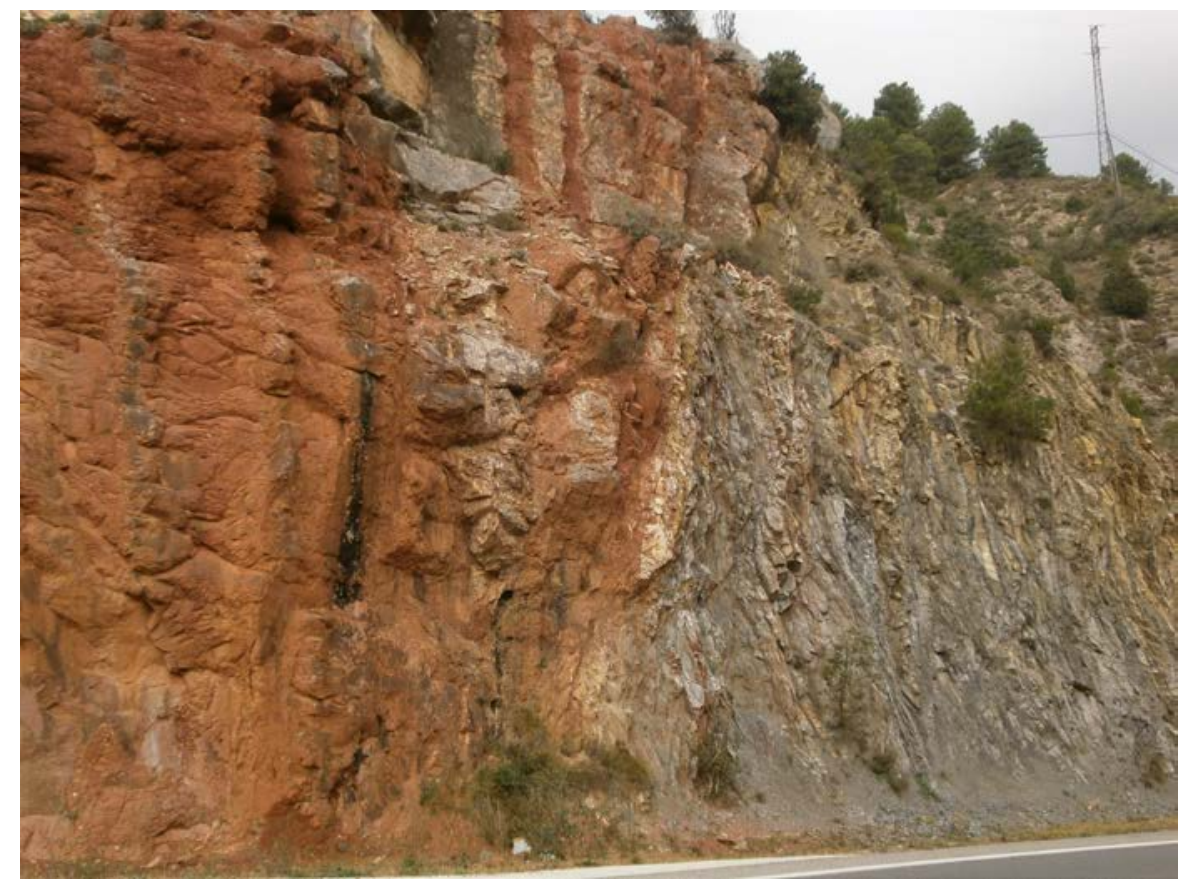

Fotografia 1. Contacte entre el Mantell del Montsec i el Mantell de Bóixols, a Coll de Nargó 


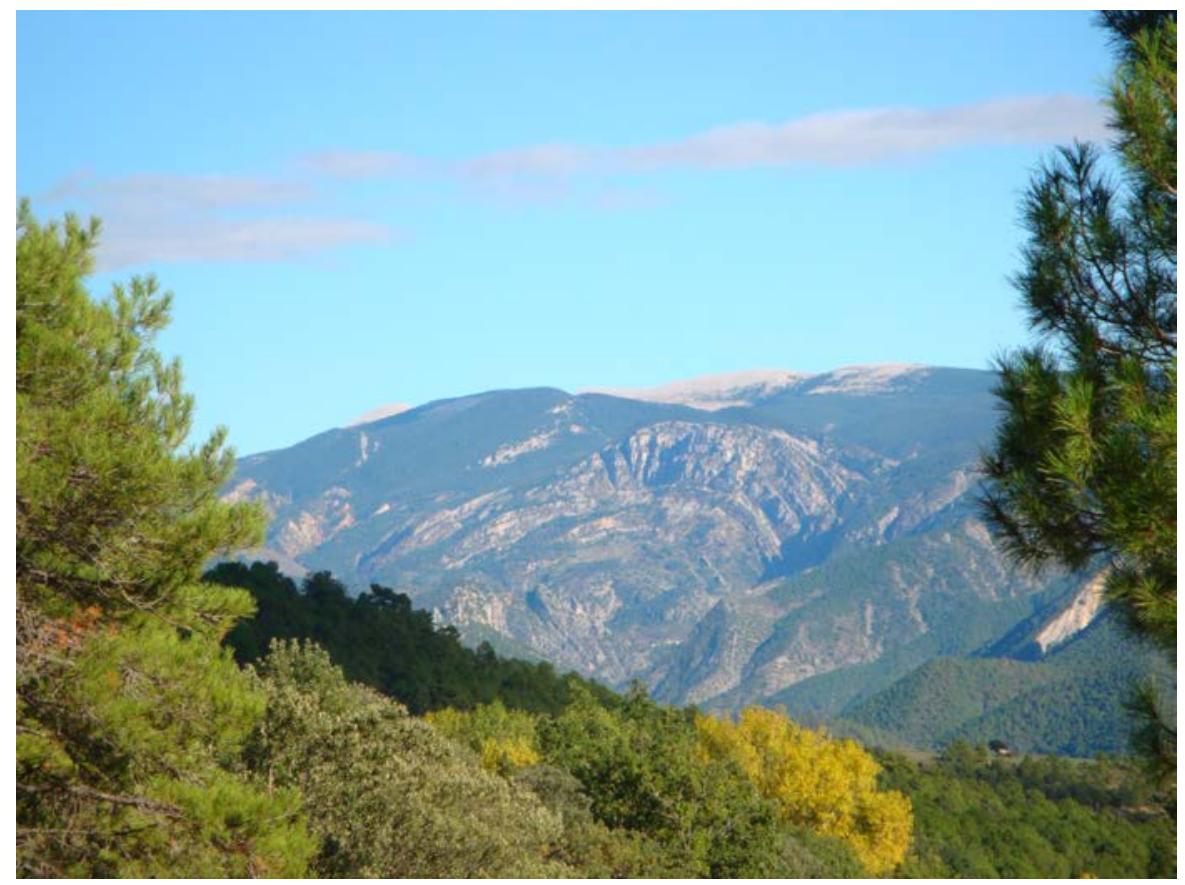

Fotografia 2. L'Anticlinal d'Alinyà, des de Coll de Nargó. Octubre 2012

Aquest contacte, es realitza per l'encavalcament del segon sobre el primer; es a dir de les calcàries del Cretàcic Inferior del Mantell de Bóixols (amb tonalitats grisenques) sobre el paleogen detrític del Mantell del Montsec tonalitats rogenques)

També cal dir, que si s'escau, es pot visitar el Museu de Paleontologia de Coll de Nargó, on hi ha molta informació sobre les recents troballes d'ous de dinosaures dels voltants de Coll de Nargó, a ponent del poble.

\subsection{Parada 2. FORN DE CALÇ DE COLL DE NARGÓ. CARRETERA C - 14, (terme municipal de Coll de Nargó, comarca de l’Alt Urgell). (Full 291).}

Després de realitzar l'aturada anterior, cal fer un curt recorregut per la carretera $C-14$, anat cap al Nord, cap a Organyà. A menys de $0^{\prime} 5 \mathrm{Km}$ de I'anterior parada, es trobarà un camí ascendent, a l'esquerra de la carretera, que condueix cap a un antic forn de calç. En aquest indret, farem una nova aturada.

Aquest recorregut, I'haurem efectuat totalment entre afloraments dels materials cretàcics del Mantell de Bóixols, on estem ara situats.

Cal dir que aquests materials han estat explotats a diversos indrets, com per les immediacions del lloc de la present aturada. Aquí eren emprats per a la fabricació de cal, en un antic forn de calç industrial. (fotografia 3). Al respecte d'aquest forn, cal dir que forma part del patrimoni miner de la comarca de I'Alt Urgell. A I'igual que uns altres elements similars, situats al Sud de la població, a l'esquerra de la carretera que condueix cap a Oliana, la carretera C - 14 . 


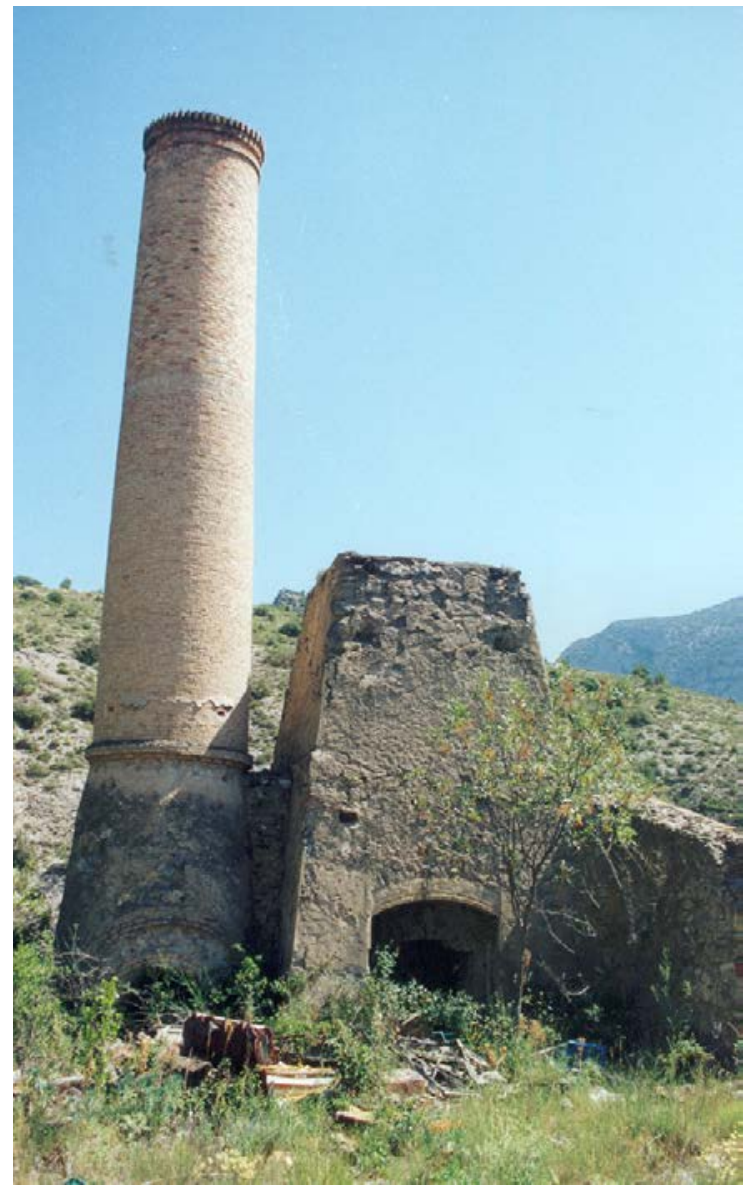

Fotografia 3. Antic forn de calç industrial, de Coll de Nargó. Octubre 2002

\subsection{Parada 3 - CONDICIONAL. GRAVERES DE LES VINYAS, (termes municipals d’Organyà i de Coll de Nargó, comarca de l'Alt Urgell). (Full 291).}

Després de realitzar la parada anterior, cal fer un nou recorregut, anant cap el Nord, per la carretera autonòmica $C-14$. Així, arribarem al Pont de l'Espià. Just en trobar-lo, veurem una gravera a l'esquerra de la carretera. En aquest indret, si s'escau, podem fer una nova aturada, a uns 2 '5 Km de la parada anterior.

En aquest recorregut, hem anat circulant en tot moment, per entre els afloraments dels materials cretàcics carbonatats, que formen part del Mantell de Bóixols, per on estem situats. Així, s'han fet ben patents els relleus del Tossal de Balinyó, situat al llevant de la carretera del Pont de l’Espià a Fígols d’Organyà. (fotografia 4) 


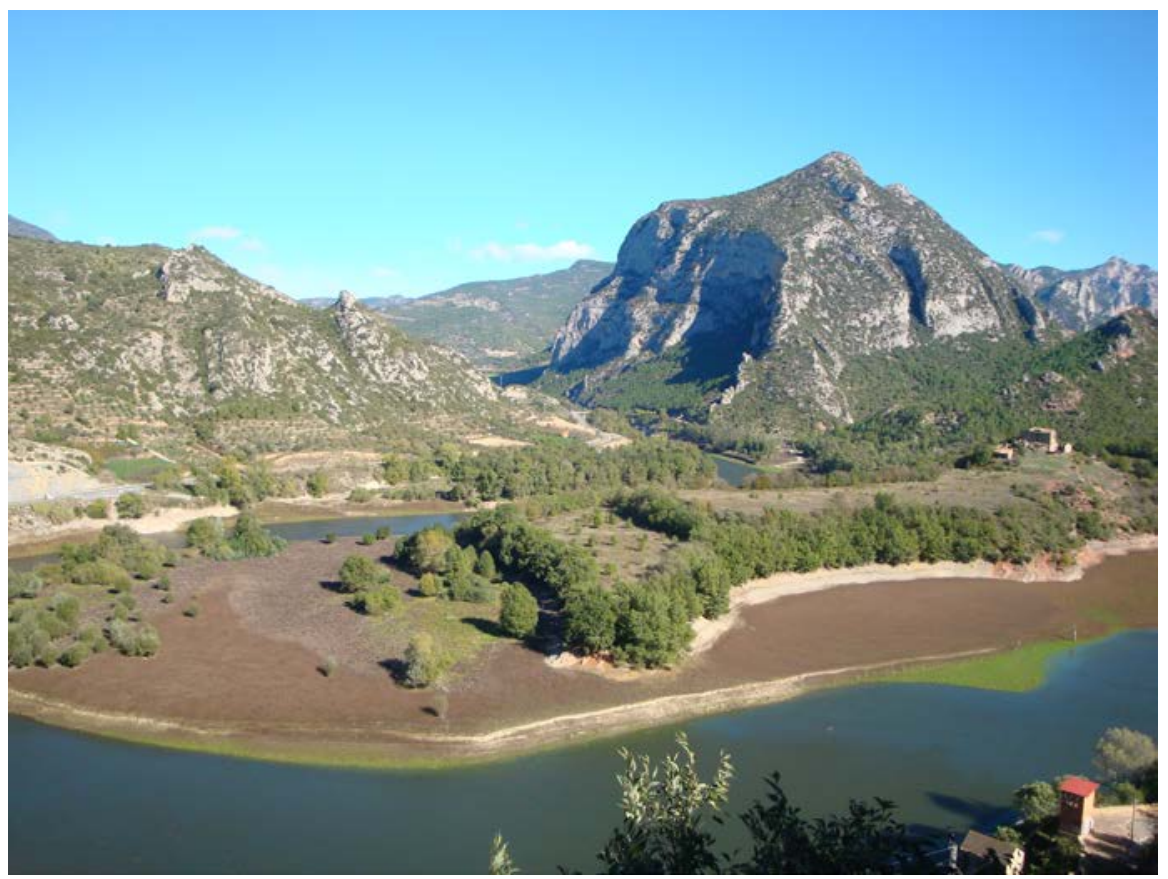

Fotografia 4. El Tossal de Balinyó, prop del Pont de l'Espià, termes de Coll de Nargó i de Fígols d'Organyà - Alinyà. Meandre del Segre a la cua de l'embassament d'Oliana. Octubre 2002

En aquest indret, hi ha una antiga explotació d'àrids. Es tracta del materials al-luvials: que formen part de les terrasses fluvials del riu Segre, concretament de la terrassa baixa. Observant aquests materials, es pot fer un estudi dels còdols. Així, es pot observar la gran granulometria dels mateixos, degut a la proximitat a trams alts del riu. Efectivament, els sediments transportats, encara que han estat arrodonits, s'han fragmentat poc. Tanmateix es pot veure com hi ha una clara preponderància dels còdols de caràcter carbonatat.

\subsection{Parada 4. ESGLÉSIA DE FIGOLS D’ORGANYÀ (terme municipal de Fígols d'Organyà - Alinyà, comarca de l'Alt Urgell). (Full 253).}

Des de la parada anterior, caldrà continuar per la carretera local que comença al Pont de I'Espià, la L - 401 (que condueix cap a Sant Llorenç de Morunys). Després de sobrepassar el riu Segre, trobarem una altra carretera local, la qual ens conduirà cap el poble de Fígols d'Organyà. Aquí farem una nova aturada, al costat de I'Església Parroquial. Així, haurem fet un recorregut proper als $3 \mathrm{Km}$, des de la parada anterior.

En aquest recorregut, ens haurem estat desplaçant entre els materials carbonatats del Mantell de Bóixols. Així, haurem passat als peus del relleu del Tossal de Balinyó, que hem vist a l'aturada anterior. Tanmateix, haurem vist com a la part septentrional d'aquest tossal, hi ha un sinclinal molt ben marcat.

En arribar a Fígols d'Organyà, es fa ben palesa una ampla cubeta d'erosió, anomenada la Ribera d'Organyà, i on es situa la veïna població del mateix nom. Aquesta cubeta es troba excavada entre els materials calcolutítics del Cretàcic Inferior i Mig. 
Precisament, des de l'indret de la parada, es pot gaudir d'un bon lloc d'observació d'aquesta cubeta. I també, tot mirant cap a l'Oest, es poden entreveure els relleus de l'Anticlinal de Bóixols i del Sinclinal de Santa Fe, donats de Sud a Nord. Aquests dos accidents formen part del Mantell de Bóixols. El primer, per d'altra banda, forma part de la Muntanya de Nargó; mentre que el segon constitueix part de la Muntanya de Santa Fe, integrant de la Serra de Boumort. (fotografia 5).

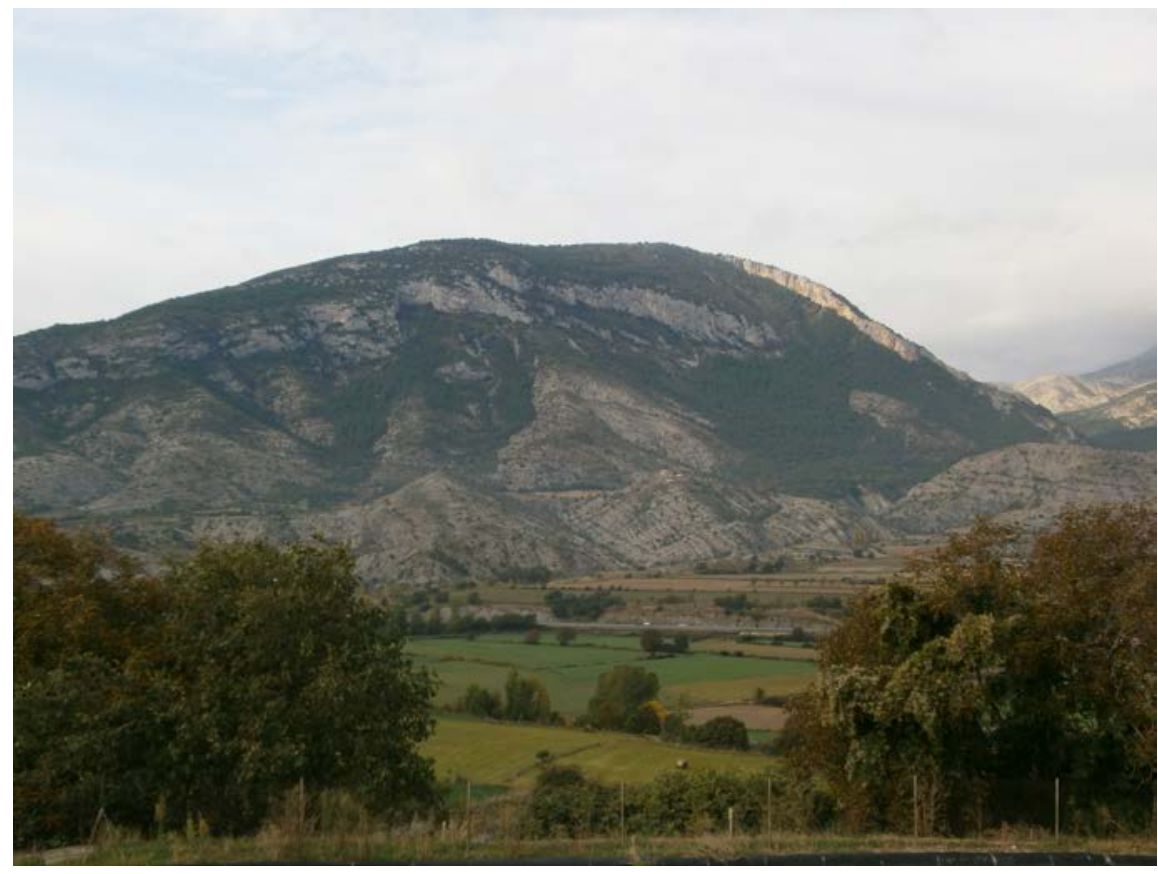

Fotografia 5. Anticlinal de Bóixols, situat sobre la Muntanya de Nargó. Mantell de Bóixols Observació des de l’Església de Fígols d’Organyà.

Octubre del 2013

\subsection{Parada 5. CONGOST DE TRES PONTS, IMMEDIACIONS DE I'HOSTAL NOU, (termes municipals d'Organyà i de Fígols d'Organyà - Alinyà, comarca de I'Alt Urgell). (Full 253).}

Després de realitzar l'aturada anterior, cal anar cap el proper poble d'Organyà, travessant de nou el riu Segre. Tot seguit, ens caldrà continuar cap el Nord, seguint de nou la carretera autonòmica $\mathrm{C}$ - 14. Per aquesta carretera entrarem aviat $\mathrm{i}$ anirem travessant el Congost de Tres Ponts (o de Tresponts, d'Organyà o de Montant). Quasi a la sortida, podem fer una nova aturada, a uns $4 \mathrm{Km}$ de l'anterior. Si s'escau, aquesta aturada la podem realitzar prop de I'Hostal Nou, abans de la cruilla d'on eix la carretera local LV - 4001, (la qual condueix cap a Montant de Tost i cap a la Vansa).

En aquest recorregut, després de sobrepassar la Ribera d'Organyà, haurem començat a trobar afloraments dels materials carbonats mesozoics que formen part del Mantell de Bóixols. Aquests materials mesozoics pertanyen fonamentalment al Cretàcic Inferior i al mig, presentant un caràcter eminentment carbonatat. Tanmateix, cap a la part final d'aquest tram del recorregut, haurem trobat també afloraments dels materials del Juràssic, de caràcter també carbonatat, prop de l'indret de l’aturada. 
En aquest recorregut, haurem també trobat nivells lignitífers, per on es van fer prospeccions infructuoses. Aquests nivells de lignits es situen dintre del l'Aptià. Són força diferents a un lignits que es van explotar fa anys pels voltants de Coll de Nargó, els quals pertanyen al Garumnià. Aquests d’ara són més antics i pertanyen al Cretàcic Inferior.

Cal dir que aquest indret, forma part del nostre Patrimoni Geològic, per I'espectacularitat del congost. (fotografies 6 i 7).

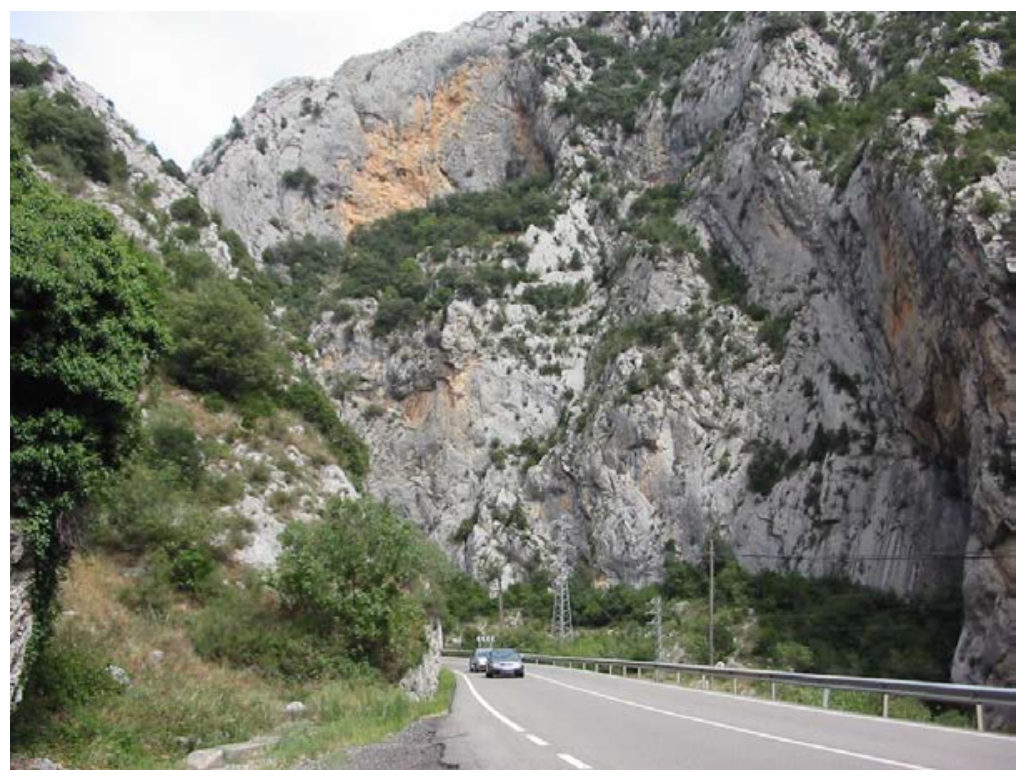

Fotografia 6. Un aspecte del Congost de Tres Ponts, pels seus sectors meridionals. Termes d'Organyà i de Fígols d’Organyà - Alinyà. Afloraments de calcàries del cretàcic Inferior

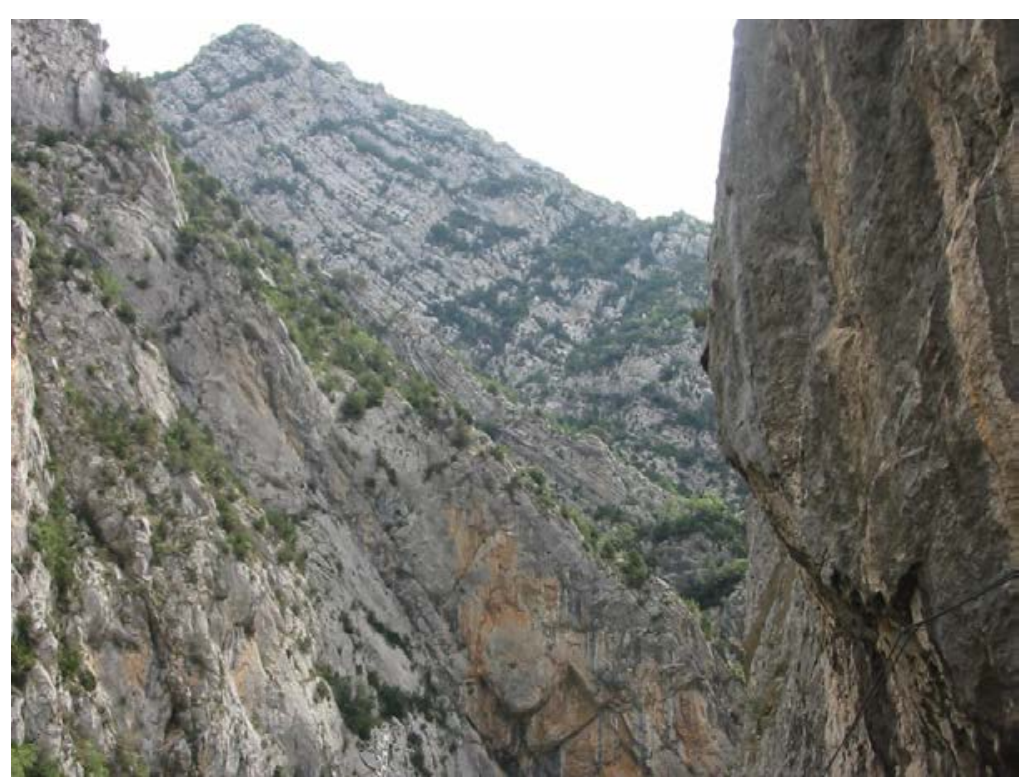

Fotografia 7. Un aspecte del Congost de Tres Ponts, pels seus sectors centrals. Termes d'Organyà i de Fígols d'Organyà - Alinyà. Afloraments de calcàries del cretàcic Inferior 


\subsection{Parada 6. IMMEDIACIONS DE CAL MATIES (la Palanca de Noves, antic terme de Noves de Segre i actualment del terme de les Valls d'Aguilar, comarca de l'Alt Urgell). (Full 253).}

Després de realitzar l'aturada anterior, cal seguir cap el Nord per la carretera autonòmica $L$ 14. Així, després de sobrepassar la cruïlla per la dreta amb la carretera LV - 4001, (la qual condueix cap a Montant de Tost i cap a la Vansa), es trobarà també per la dreta la carretera local que condueix cap a Castellar de Tost, Tost i Torà de Tost. També per l'esquerra es trobarà la carretereta que s'adreça cap a Hostalets de Tost (que travessarem en part). Finalment s'arribarà a Cal Maties, quasi en trobar, per l'esquerra, la carretera LV - 5134 (que condueix cap a Noves de Segre). En aquest indret, a la Palanca de Noves, farem una nova aturada, la darrera d'aquest itinerari. Així, des de l'anterior, haurem recorregut uns $5 \mathrm{Km}$, aproximadament.

En aquest recorregut, haurem travessat els materials carbonats que hem esmentat a l'aturada anterior, els quals pertanyen al Juràssic, situant-se dintre del Mantell de Bóixols. Tot i així, ben aviat haurem començat a trobar afloraments dels materials triàsics del Keuper. Així, haurem creuat l'encavalcament del Mantell de les Nogueres, sobre el Mantell de Bóixols, el qual es realitza mitjançant els nivells d'argiles y guixos triàsics del Keuper.

Després, haurem trobat afloraments dels materials triàsics del Buntsandsteim i de nou del Keuper. També, més amunt haurem trobat els materials detrítics del Permotries. I més amunt els del Carbonífer, que ja no arribarem a tallar. Tots aquests materials es situen dintre del Mantell de les Nogueres, on estem ara situats.

Ara, pels voltants de Cal Maties apareixen afloraments argilosos i guixosos del Keuper, que es fan ben palesos al costat dret de la mateixa carretera, i en especial al brancal que es dirigeix cap a Cal Maties. Així, aquí es troben: CALCITA, ANHIDRITA, GUIX i HEMIHEDRITA, entre altres minerals. Es a dir: des del Pla de Sant Tirs hem anat pujant dintre de la sèrie estratigràfica. ). Tots aquests darrers materials, del Triàsic Superior i del Permotries pertanyen al Mantell de la Unitat de les Nogueres, al seu aflorament més occidental, i encavalquen als que veurem més avall prop d'Hostalets de Tost.

En aquest indret finalitza el recorregut de l'itinerari. 


\section{Bibliografia}

GUIMERÀ, J. et altri (1992).- Geologia (II), Història Natural dels Països Catalans, Vol. 2, 547 pag. Enciclopèdia Catalana, S.A. Barcelona.

MATA-PERELLÓ, J.M. (1991).- Els Minerals de Catalunya. Arxius de la Secció de Ciències de I'Institut d'Estudis Catalans, vol.47, 545 pàgines. Barcelona.

MATA-PERELLÓ, J.M. (1995).- Itinerari Geològico-Mineralògic per I'Alt Urgell: d'Oliana a la Palanca de Noves i al Pla de Sant Tirs. Selecc. d'itineraris geològico-mineralògics per l'Alt Urgell, ... pp. 3-12. Manresa.

MATA-PERELLÓ, J. M. (1998).- Recorregut de recerca geològica per les comarques de I'Alt Urgell (Urgell Mitjà) i Pallars Jussà: des d'Oliana a la Palanca de Noves i des del Coll de Nargó a Isona. Xaragall, sèrie $B, n^{\circ} 104,11$ pag. Manresa.

MATA-PERELLÓ, J. M. (2011).- Recorregut de recerca geològica i mineralògica per I'Urgell Mitjà (comarques de I'Alt Urgell i de la Noguera): des Castellciutat i la Palanca de Noves a Peramola i a Ponts. Inèdit. 11 pàgines. Manresa.

MATA-PERELLÓ, J. M. i MONTANÉ GARCÍA, P. (2002).- Recorregut de recerca geològica per les comarques de la Noguera i de I'Alt Urgell (Urgell Mitjà): des de Folquer a Peramola, a Oliana i a la Palanca de Noves. Inèdit, 11 pag. Manresa.

MATA-PERELLÓ, J. M. i MONTANÉ GARCÍA, P. (2003).- Recorregut de recerca geològica i mineralògica per I'Urgell Mitjà (comarques de la Noguera i de l'Alt Urgell: des de Ponts a Oliana i a la Palanca de Noves. Inèdit. 10 pàgines. Manresa.

RIBA ARDERIU, O. et altri (1976).- Geografia Física dels Països Catalans. Edit Ketres. Barcelona. 